\title{
Anisotropy influence on the mechanical and microstructural characteristics of AZ31B sheets deformed at room and elevated temperature
}

Cite as: AIP Conference Proceedings 2113, 170005 (2019); https://doi.org/10.1063/1.5112721

Published Online: 02 July 2019

Q. L. Wang, R. Bertolini, A. Ghiotti, and S. Bruschi

\section{Conference Proceedings}

Get $30 \%$ off all print proceedings!

\section{Enter Promotion Code PDF30 at checkout}
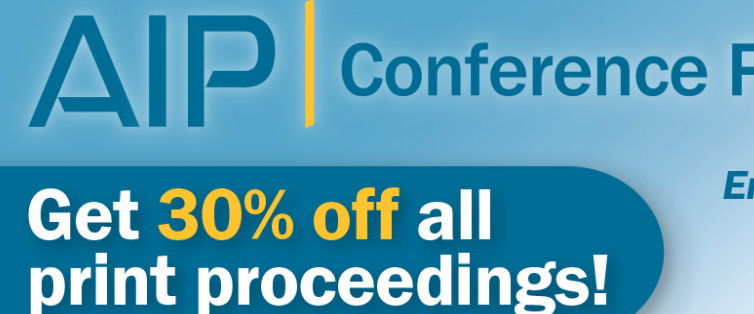


\title{
Anisotropy Influence on the Mechanical and Microstructural Characteristics of AZ31B Sheets Deformed at Room and Elevated Temperature
}

\author{
Q.L. Wang ${ }^{1, \text { a) }}$, R. Bertolini ${ }^{1, b)}$, A. Ghiotti ${ }^{1, c)}$, S. Bruschi ${ }^{1, d)}$ \\ ${ }^{1}$ Department of Industrial Engineering, University of Padova, Via Venezia 1, 35131, Padova, Italy \\ a)Corresponding author: qiaoling.wang@studenti.unipd.it \\ b)rachele.bertolini@phd.unipd.it \\ c)andrea.ghiotti@unipd.it \\ d)stefania.bruschi@unipd.it
}

\begin{abstract}
The objective of the present study is to evaluate the anisotropy influence on the mechanical and microstructural characteristics of AZ31B magnesium alloy sheets deformed at room and elevated temperature. To this aim, uniaxial tensile tests were carried out along the rolling, transverse and diagonal direction in the range of temperatures from room temperature to $300^{\circ} \mathrm{C}$ at $0.1 \mathrm{~s}^{-1}$. The Lankford coefficients, ultimate tensile strength, diffuse necking strain and fracture strain values were evaluated as a function of the testing temperature and specimen orientation. Furthermore, microstructural features were analysed as well as micro-hardness was measured for each testing condition to assess the post-deformation characteristics.
\end{abstract}

\section{INTRODUCTION}

Magnesium alloys can represent an alternative to aluminum alloys for producing lightweight parts of vehicles, thanks to their high strength-to-weight ratio [1]. Magnesium sheets with a hexagonal close-packed atomic structure develop a strong (0001) basal texture during rolling [2], with the c-axis parallel to the thickness direction, which makes the deformation along the thickness direction restricted and, therefore, promotes early failure. This trait is particularly detrimental when the sheets are deformed at room temperature. Deformation modes of magnesium alloys include basal slip, prismatic slip, pyramidal slip and twinning. The flow stress of a polycrystal is determined by the Critical Resolved Shear Stress (CRSS) of the deformation mechanisms. It is generally assumed that, at low temperatures, $\mathrm{CRSS}_{\text {basal }}<\mathrm{CRSS}_{\text {twinning }}<\mathrm{CRSS}_{\text {prismatic }}<\mathrm{CRSS}_{\text {pyramidal }}[3,4]$. On the contrary, at higher temperatures, more slip systems become active leading to an overall enhancement of the magnesium sheets formability [5]. In [6,7] it was found that the change in the orientation of twinned grains at moderate temperatures might cause hardening or softening on the basis of the initial sheet texture. At higher temperature, the fracture strain is higher indicating more ductile behaviour, since grains are refined after recrystallization as well as the CRSS values for the different slip modes including twinning are closer. Sheet anisotropic characteristics are reported in [8] till $200^{\circ} \mathrm{C}$, showing larger Lankford coefficients at high strain rate. The temperature influence on the Lankford coefficients of AZ31 magnesium alloy sheets at high strain rate is reported in [9]. However, much less literature records are available about the anisotropy effect on Lankford coefficients, diffuse necking strain and fracture strain at elevated temperature.

To this regard, the paper presents the anisotropy influence on the flow behavior and fracture onset of AZ31B magnesium alloy sheets deformed at elevated temperature. To do that, tensile tests were carried out in a wide range temperature, from room temperature to $300^{\circ} \mathrm{C}$, on specimens cut at different rolling direction. Microstructure and micro-hardness after deformation were evaluated as well to assess the post-deformation characteristics. 


\section{EXPERIMENTAL}

The material used in present paper is the AZ31B magnesium alloy, provided in form of $1 \mathrm{~mm}$ thick sheets in annealed condition (see microstructure in Fig. 1(a)). Dog-bone like specimens for uniaxial tensile testing were laser cut from the sheets with respect to the rolling $\left(0^{\circ}\right)$, diagonal $\left(45^{\circ}\right)$, and transverse direction $\left(90^{\circ}\right)$. The uniaxial tensile tests were carried out at a strain rate of $0.1 \mathrm{~s}^{-1}$ on a MTS ${ }^{\mathrm{TM}}$ universal testing machine equipped with a resistance heating system. The testing temperature ranged from $25^{\circ} \mathrm{C}$ to $300^{\circ} \mathrm{C}$. For each testing temperature, the tests were carried out using specimens at varying rolling direction. Each test was repeated at least twice to confirm the reliability of the results. The specimen dimensions and experimental setup are shown in Fig. 1(b-c). Each specimen was painted with a random pattern to allow the deformation recordings through a high-speed camera during the test. The Aramis ${ }^{\mathrm{TM}}$ Digital Image Correlation (DIC) system was then used to analyze the recorded images and get the true strain values till fracture. Specimens close to the fracture surfaces were cut, polished and then etched (using a solution made of $30 \mathrm{ml}$ acetic acid, $15 \mathrm{ml}$ water, $6 \mathrm{ml}$ picric acid and $100 \mathrm{ml}$ ethanol) for $5 \mathrm{~s}$ to analyze the microstructure by a Leica DMRE ${ }^{\mathrm{TM}}$ optical microscopy equipped with a high definition digital camera. On the same

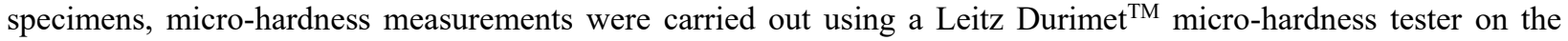
cross section perpendicular to the loading direction at regular distance intervals, using a $15 \mathrm{~g}$ load for $30 \mathrm{~s}$, four values were recorded for measurement and then the average value calculated.

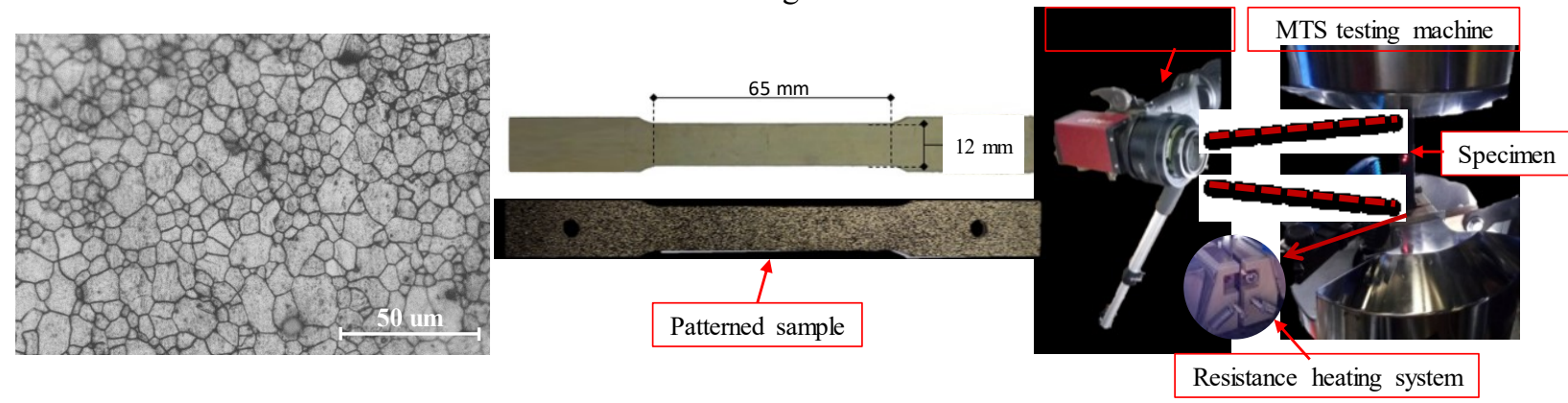

(a)

(b)

(c)

FIGURE 1. (a) Microstructure of the as-received AZ31B sheets, (b) geometry of the specimens used for tensile testing ,and (c) $\mathrm{MTS}^{\mathrm{TM}}$ testing machine equipped with the resistance heating and Aramis ${ }^{\mathrm{TM}}$ systems.

\section{RESULTS AND DISCUSSION}

\section{Flow Behaviour}

The Ultimate Tensile Strength (UTS), namely the maximum stress value in the engineering stress-strain curve, is shown in Fig. 2 (a) as a function of temperature and specimen rolling direction for a strain rate equal to $0.1 \mathrm{~s}^{-1}$. As expected, the UTS values decrease at increasing temperature regardless of the specimen orientation. The UTS values are higher at $90^{\circ}$ rolling direction than at $0^{\circ}$ and $45^{\circ}$ at room temperature and $100^{\circ} \mathrm{C}$, whereas the differences between $200^{\circ} \mathrm{C}$ and $300^{\circ} \mathrm{C}$ are almost negligible. The same sensitivity was presented in [10,11]. The Lankford coefficients $R$, evaluated as the ratio between the strains in the specimen width and thickness, are reported in Fig. 2 (b). A point at the center of the necked area on the specimen surface was selected as measuring point, according to the procedure reported in [12]. The Lankford coefficients here reported are representative of the steady state region of the true strain - $R$ curve as acquired through the Aramis ${ }^{\mathrm{TM}}$ system. The $R$ values are always higher than 1 regardless of the testing temperature and specimen rolling direction, due to the fact that one of the main deformation mechanisms is the prismatic $<\mathrm{a}>$ slip resulting in greater strain in the width than in the thickness direction $[13,14,15]$. An increase of the $R$ values is shown from room temperature to $100^{\circ} \mathrm{C}$, and then a decrease until $250^{\circ} \mathrm{C}$, with almost the same values kept at $300^{\circ} \mathrm{C}$. It is worth noting that still high $R$ values demonstrate a strong participation of prismatic $<\mathrm{a}>$ slip on the overall deformation mechanisms. The increase of anisotropy from room temperature to $100^{\circ} \mathrm{C}$ can be explained by easy slip of $<\mathrm{a}>$ on basal and prismatic planes, while, at temperatures above $100^{\circ} \mathrm{C}$, the pyramidal $<\mathrm{c}+\mathrm{a}>$ slip is more and more influential, leading to $R$ values reduction. The same trend is reported in [14] in case of coarse grained sheets. The more anisotropic behavior evident at $90^{\circ}$ rolling direction can be a consequence of the transition from basal to non-basal $<\mathrm{a}>$ slip systems $[13,16]$. 
Fig. 3 (a) reports the width strain - true strain and thickness strain - true strain curve at different specimen orientation at room temperature: at $90^{\circ}$ rolling direction, the width strain is larger as well as the thickness strain is smaller compared to the rolling and $45^{\circ}$ direction. If straining happens along the thickness direction, the contraction along the c-axis due to twinning or pyramidal slip must occur. However, the CRSS is higher on c-axis direction, which makes the width direction experience more strain than the thickness direction. This is also observed in paper [17]. The same was observed at the other testing temperatures, and therefore not here reported.

Fig. 3 (b) shows that the average normal anisotropy is always higher than 1.5, which means much less deformation on the thickness direction than on the width direction, namely the thickness resistance is high to avoid localized thinning. On the contrary, the planar anisotropy is close to 0 , which means ears will not develop during deep drawing processes. The same outcomes are given in [18].
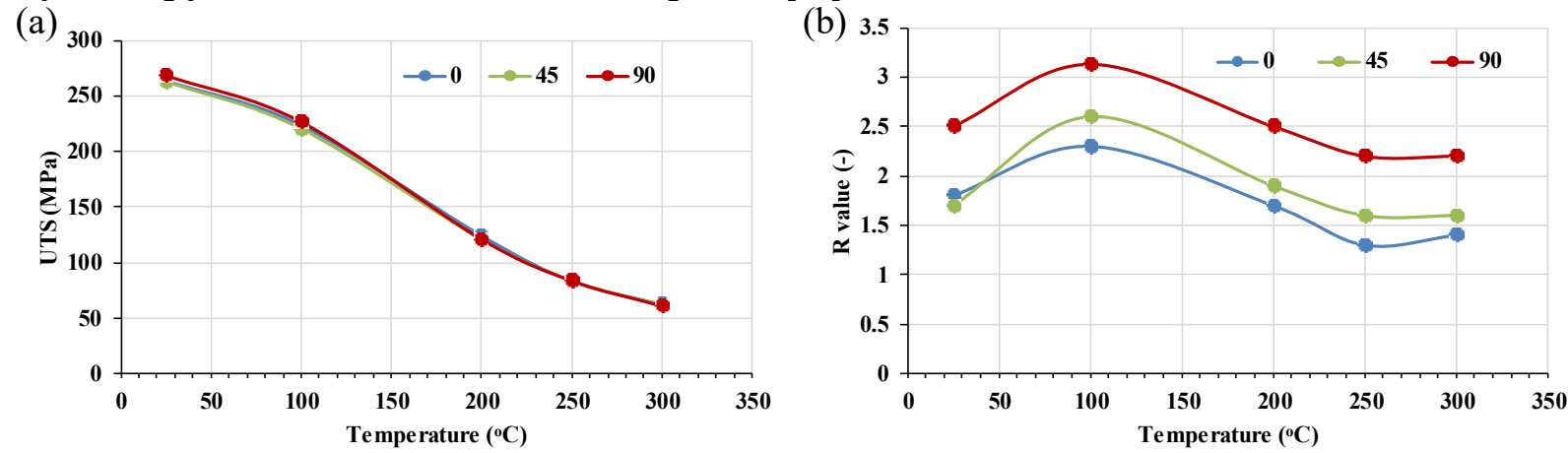

FIGURE 2. (a) UTS, and (b) $R$ values as a function of the testing temperature and specimen rolling direction
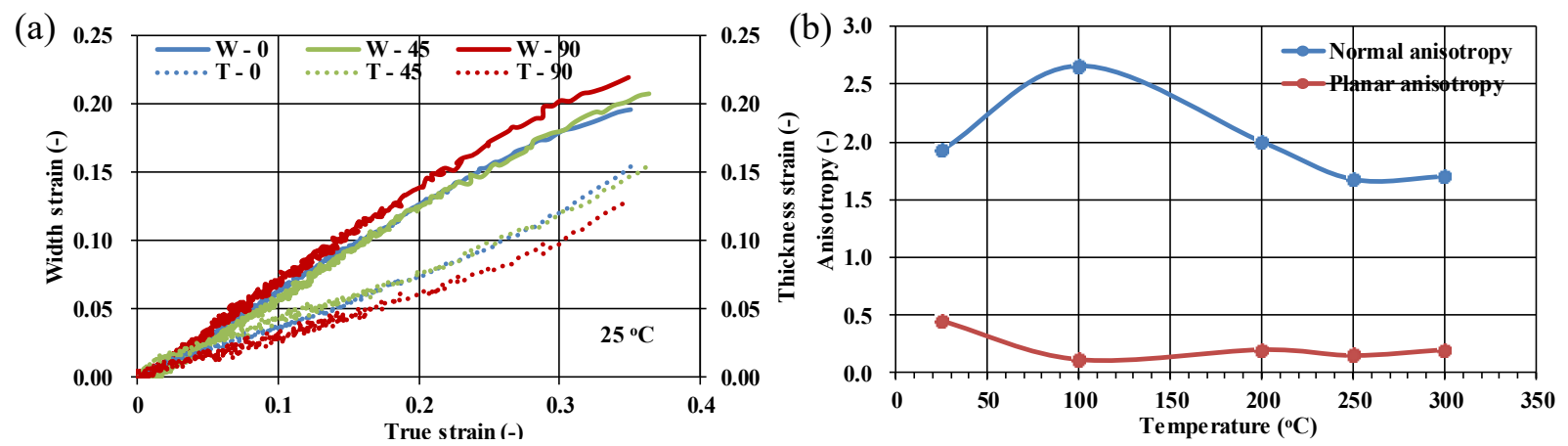

FIGURE 3. (a) Width and thickness strains as a function of specimen rolling direction at room temperature, and (b) average normal and planar anisotropy at varying temperature.

The strain at diffuse necking, also called instability strain, is identified when necking starts developing showing a symmetric decrease of the width of the specimen. The value is the true strain at UTS. Fig. 4 (a) reports the diffuse necking strain as a function of the testing temperature and specimen rolling direction: specimens cut at $90^{\circ}$ with respect to the rolling direction show earlier the onset of diffuse necking. In addition, the width strain is larger at $90^{\circ}$ direction, which is also consistent with the diffuse necking appearing earlier at $90^{\circ}$ direction (Fig. 3(a)). The instability strain increases up to $100^{\circ} \mathrm{C}$ and then decreases regardless of the specimen rolling direction. This different behavior is due to the deformation mechanism: at room and $100^{\circ} \mathrm{C}$, plastic deformation is mainly controlled by twinning (Fig. 5) [19]. On the other hand, above $100^{\circ} \mathrm{C}$, at increasing temperature, mechanical twinning effect decreases whereas dislocation motion is enhanced as a consequence of the activation of more slip systems as well as recrystallization occurred making the microstructure finer (Fig. 5): both these phenomena promote the development of diffuse necking.

The fracture strain at varying testing temperature and specimen rolling direction is shown in Fig. 4 (b). The strain at fracture increases at increasing temperature, regardless of the specimen rolling direction, nevertheless being always the highest at $45^{\circ}$ rolling direction. Below $100^{\circ} \mathrm{C}$, even if twinning is active as deformation mechanism, the lowest ductility is due to the twins that act as barriers for the dislocation motion [20]; on the other hand, above $200^{\circ} \mathrm{C}$, the activation of non-basal slip systems increases the ductile behavior, while the effect of mechanical 
twinning is reduced deformation, being the temperature of $200^{\circ} \mathrm{C}$ the activation temperature of additional slip systems [21].
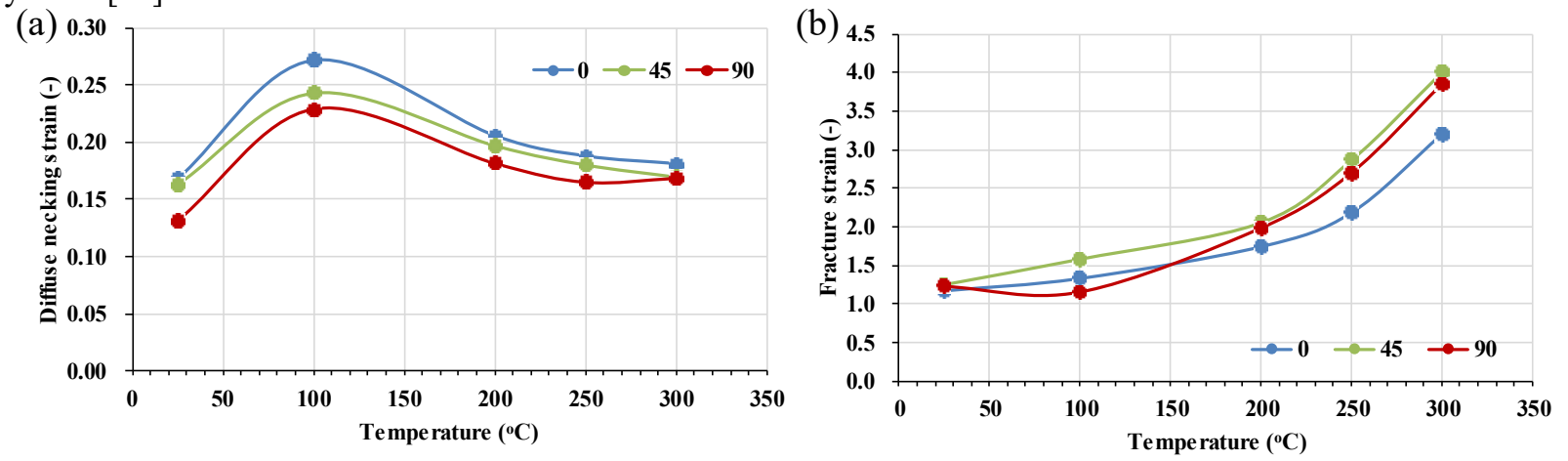

FIGURE 4. (a) Diffuse necking strain, and (b) fracture strain as a function of the testing temperature and specimen rolling direction.

\section{Microstructural and Micro Hardness Features}

The as-received microstructure of the AZ31 sheets (Fig. 1(a)) shows a dual grain size distribution, which is likely the result of dynamic recrystallization during hot rolling. Fig. 5 reports the microstructure of the deformed specimens at varying testing temperature and specimen rolling orientation. As expected, the grain size decreases at increasing temperature. Both at room temperature and $100^{\circ} \mathrm{C}$, a large number of twins is visible in all the rolling directions, indicating that twinning was the dominant deformation mechanism at relatively low temperatures. On the contrary, above $100^{\circ} \mathrm{C}$, twins disappear, some small grains start forming along the grain boundaries of coarser grains as a consequence of the onset of dynamic recrystallization, with an increasing grain refinement at $250^{\circ} \mathrm{C}$ and $300^{\circ} \mathrm{C}$. No significant differences in the microstructure were found at different specimen orientation, meaning that there is no anisotropy sensitivity on microstructure.

Fig. 6 (a-c) reports the grain size distribution in the as-received sheet and nearby the fracture zone at room temperature and $300^{\circ} \mathrm{C}$. The grain size measured using the line intercept method. In the as-received sheet, the Average Grain Size (AGS) is approximately $9 \mu \mathrm{m}$ with a high Standard Deviation (SD) equal to $4.8 \mu \mathrm{m}$, meaning a highly inhomogeneous microstructure. The AGS is smaller at room temperature, namely $5.4 \mu \mathrm{m}$, as a consequence of the specimen straining, and even smaller at $300^{\circ} \mathrm{C}$, namely $3.5 \mu \mathrm{m}$, as a consequence of dynamic recrystallization, which makes the microstructure much more homogeneous.

Fig. 6 (d) shows the Vickers micro-hardness after deformation of the same specimens, which increases at temperature increase as a consequence of the grain size refinement, which is consistent with Hall-Petch equation.

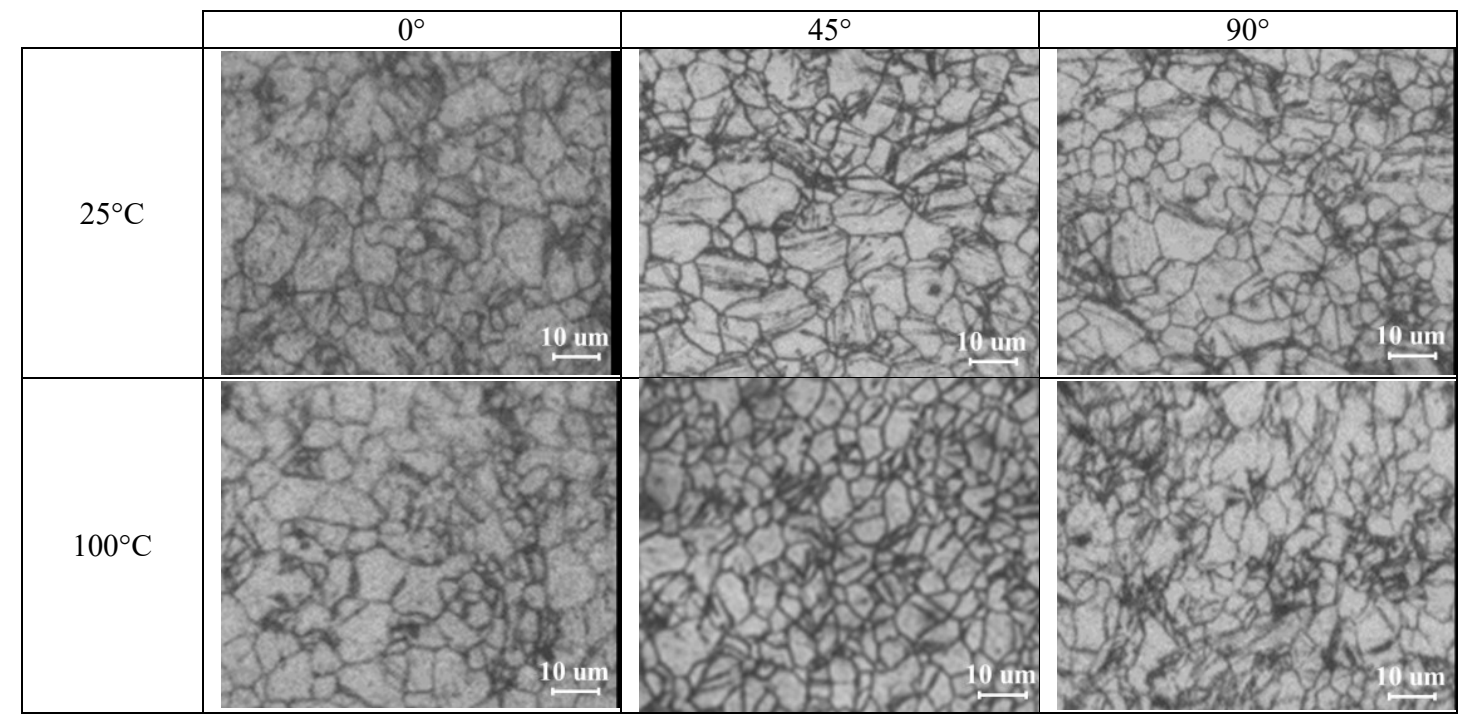




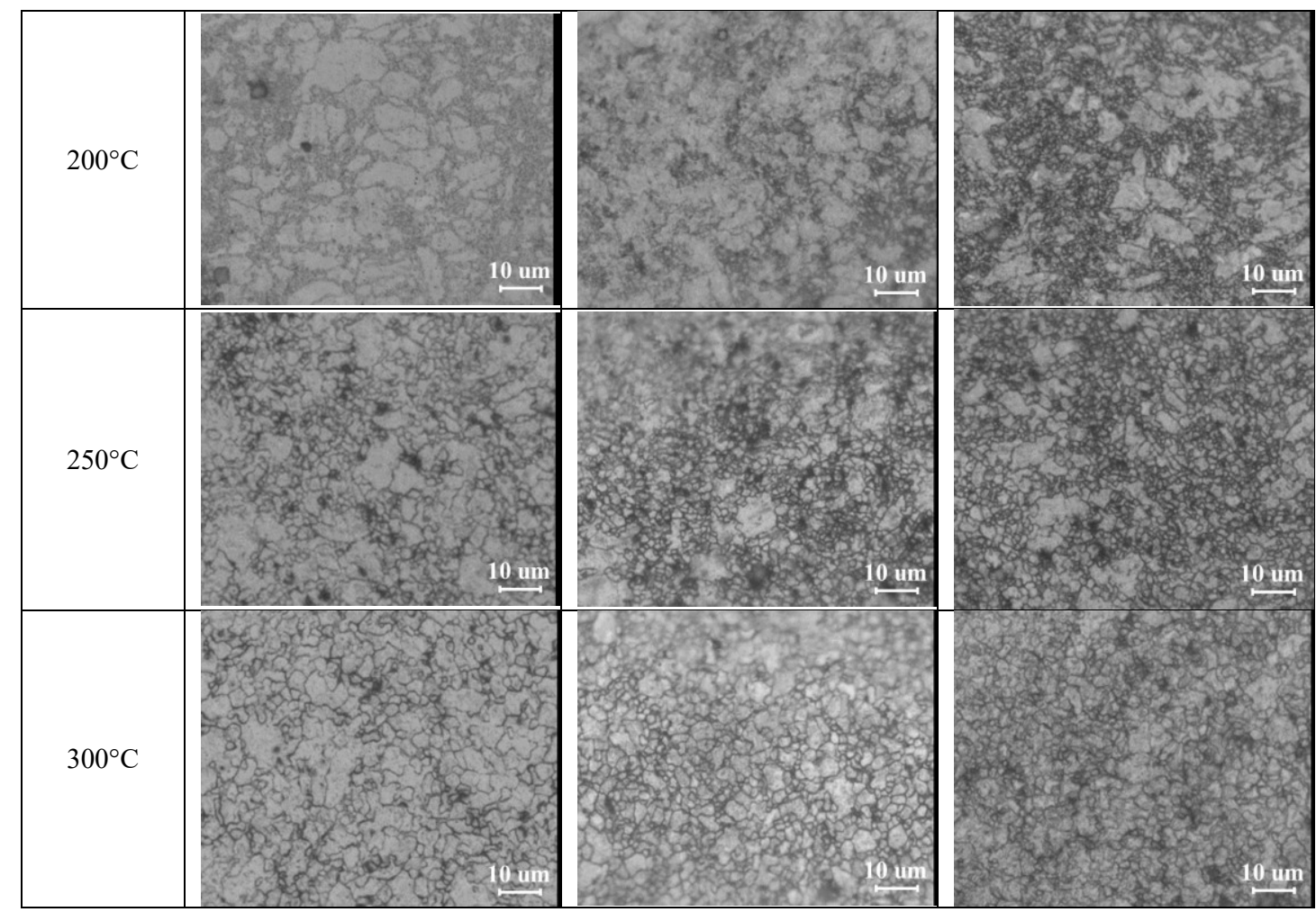

FIGURE 5. Microstructure after deformation as a function of the testing temperature and specimen rolling direction.

(a)

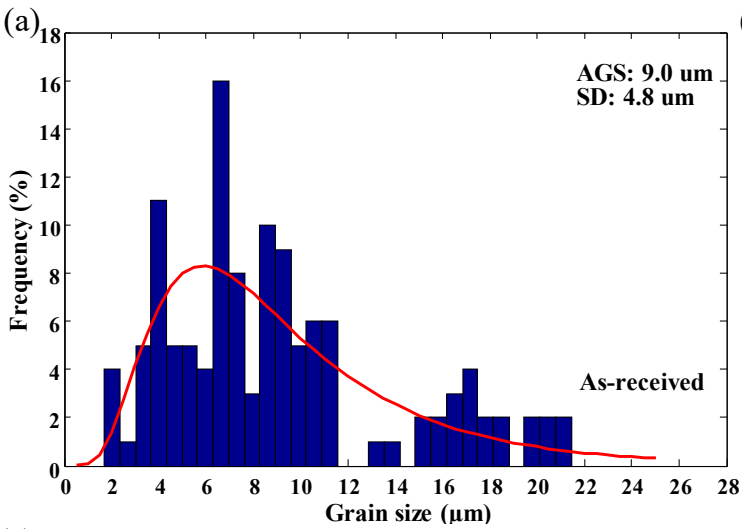

(c)

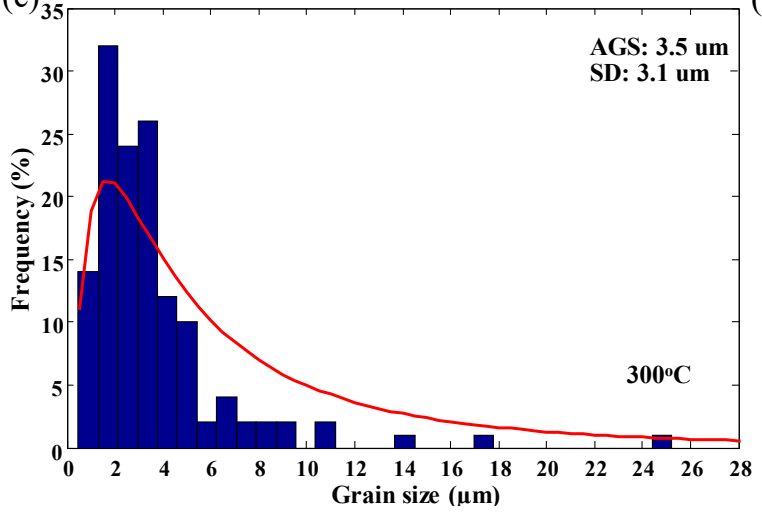

(b)

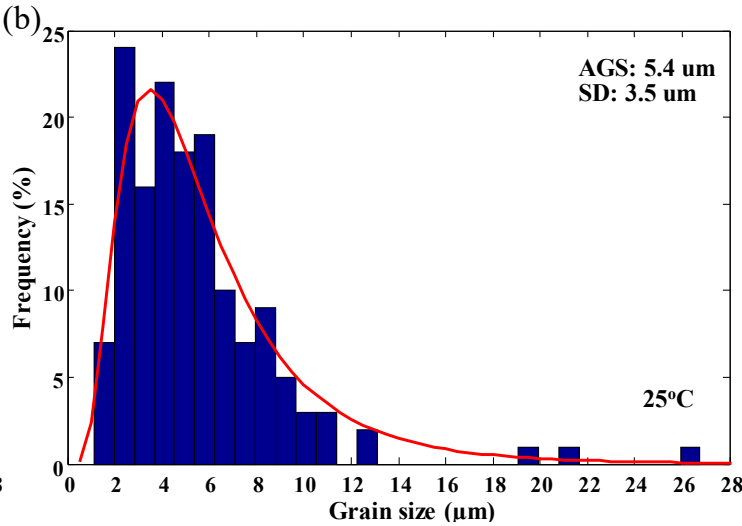

(d)

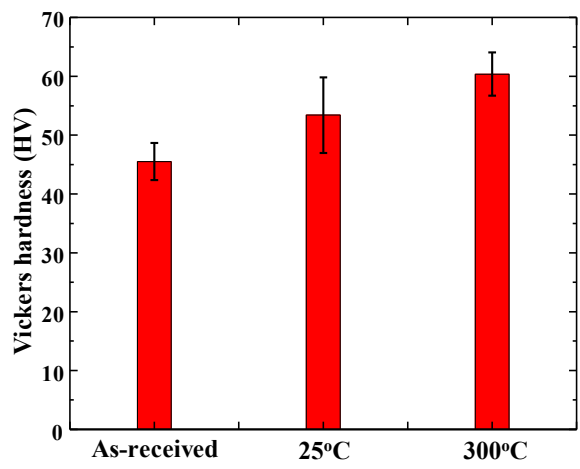

FIGURE 6. Grain size distribution of sheets in: a) as received condition, b) at $25^{\circ} \mathrm{C}$, c) at $300^{\circ} \mathrm{C}$, and d) Vickers micro-hardness as a function of testing temperature at rolling direction. 


\section{CONCLUSIONS}

The paper shows the anisotropy influence on the mechanical and microstructural characteristics of AZ31B sheets deformed at room and elevated temperature based on uniaxial tensile tests. The obtained results shows that the diffuse necking strain is higher at rolling direction with the maximum value shown at $100^{\circ} \mathrm{C}$, whereas, the highest ductility is shown at $45^{\circ}$ rolling orientation, regardless of the testing temperature. This proves the need to consider the anisotropy influence when modelling sheet forming processes carried out on AZ31 sheets even at elevated temperature. On the contrary, the influence of the specimen rolling direction on the microstructure is negligible.

\section{ACKNOWLEDGMENTS}

The financial support of the China Scholarship Council (CSC) (No. 201608370094) is gratefully acknowledged.

\section{REFERENCES}

1. B. L. Mordike and T. Ebert, Mater. Sci. Eng. A302, 37-45 (2001).

2. A. D. Rollett and S. I. Wright. "Typical textures in metals". In Texture and Anisotropy. Edited by U. F. Kocks, C. Tomé, H. R. Wenk (Cambridge University Press, Cambridge, UK, 2000), pp. 178-238.

3. A. Styczynski, C. Hartig, J. Bohlen and D. Letzig, Scr. Mater. 50, 943-947 (2004).

4. M. R. Barnett, Metall. Mater. Trans. A. 34, 1799-1806 (2003).

5. I. Ulacia, N. V. Dudamell, F. Galvez, S. Yi, M. T. Perez-Prado and I. Hurtado, Acta. Mater. 58, 2988-2998 (2010).

6. L. Jiang, J. J. Jonas, A. A. Luo, A. K. Sachdev and S. Godet, Scr. Mater. 54, 771-75 (2006).

7. L. Jiang, J. J. Jonas, A. A. Luo, A. K. Sachdev and S. Godet, Metall. Mater. Trans. A, 445, 302-309 (2007).

8. D. G. Tari and M. J. Worswick. AIP Conference Proceedings, ESAFORM 2011, edited by Gary Menary (Belfast, United Kingdom, 2011). Vol.1353, pp. 1547-1552.

9. Y. Y. Liu, P. L. Mao, F. Zhang, Z. Liu and Z. Wang, Philos. Mag.1-19 (2018).

10. J. Y. Lee, D. Steglich and M. G. Lee, Int. J. Plast. 105, 1-23 (2018).

11. X. P. Chen, D. Shang, R. Xiao, G. J. Huang and Q. Liu, Trans. Nonferrous Met. Soc. China, 20, 589-593 (2010).

12. J. D. Kang, D. S. Wilkinson, R. K. Mishra, W. Yuan and R. S. Mishra, Mater. Sci. Eng. A. 567, 101-109 (2013).

13. S.R.Agnew and O.Duygulu, Int. J. Plast. 21, 1161-1193 (2005).

14. D. L. Atwell, M. R. Barnett and W. B. Hutchinson, Mater. Sci. Eng. A. 549, 1-6 (2012).

15. A. Jain and S. R. Agnew, Mater. Sci. Eng. A. 462, 29-36 (2007).

16. X. Y. Lou, M. Li, R. K. Boger, S. R. Agnew and R. H. Wagoner, Int. J. Plast. 23, 44-86 (2007).

17. B. Kondori and A. A. Benzerga, Metall. Mater. Trans. A. 45, 3292-3307 (2014).

18. H. Zhang, G. S. Huang, J. F. Fan, H. J. Roven, F. S. Pan and B. S. Xu, Mater. Sci. Eng. A.608, 234-241 (2014).

19. F. Berge, L. Krüger, M. Ullmann, C. Kbetschek and R. Kawalla, Mater. Today. 2S, 233-241 (2015).

20. A. Serra, D. J. Bacon and R. C. Pond, Metall. Mater. Trans. 33, 809-812 (2002).

21. F. Berge, L. Krüger, H. Ouaziz and C. Ullrich, Trans. Nonferrous Met. Soc. China, 25, 1-13 (2015). 